\title{
Cost-effectiveness analysis of combination antifungal therapy with voriconazole and anidulafungin versus voriconazole monotherapy for primary treatment of invasive aspergillosis in Spain
}

\author{
This article was published in the following Dove Press journal: \\ ClinicoEconomics and Outcomes Research \\ 30 December 2016 \\ Number of times this article has been viewed
}

\author{
Santiago Grau' \\ Jose Ramon Azanza² \\ Isabel Ruiz ${ }^{3}$ \\ Carlos Vallejo ${ }^{4}$ \\ Josep Mensa ${ }^{5}$ \\ Johan Maertens ${ }^{6}$ \\ Werner J Heinz ${ }^{7}$ \\ Jon Andoni Barrueta ${ }^{8}$ \\ Carmen Peral ${ }^{9}$ \\ Francisco Jesús Mesa ${ }^{8}$ \\ Miguel Barrado ${ }^{10}$ \\ Claudie Charbonneau" \\ Darío Rubio-Rodríguez ${ }^{12}$ \\ Carlos Rubio-Terrés ${ }^{12}$ \\ 'Pharmacy Department, Hospital del \\ Mar, Universitat Autònoma de Barcelona, \\ Barcelona, ${ }^{2}$ Clinical Pharmacology \\ Department, Clínica Universidad de Navarra, \\ Pamplona, ${ }^{3}$ Infectious Diseases Department, \\ Hospital Universitari Vall d'Hebron, \\ Barcelona, ${ }^{4}$ Hematology Department, \\ Hospital Universitario Donostia, San \\ Sebastián, ${ }^{5}$ Infectious Diseases Department, \\ Hospital Clínic de Barcelona, Barcelona, \\ Spain; ${ }^{6}$ Hematology Department, University \\ Hospital Gasthuisberg, Leuven, Belgium; \\ ${ }^{7}$ Hematology/Oncology Department, \\ Medizinische Klinik und Poliklinik II, \\ Universitätsklinikum, Würzburg, Germany; \\ ${ }^{8}$ Medical Department, ${ }^{9}$ Economics \\ and Outcomes Research Department. \\ Pfizer S.L.U, Alcobendas, ${ }^{10} \mathrm{Clinical}$ Trials \\ Department, Trial Form Support, Madrid, \\ Spain; "Pharmacoeconomics Department, \\ Pfizer International Operations, Paris, France: \\ ${ }^{12}$ Pharmacoeconomics Department, Health \\ Value, Madrid, Spain
}

Correspondence: Darío Rubio-Rodríguez Health Value, C/Virgen de Aránzazu, 21. $5^{\circ} \mathrm{B}$ Madrid 28034, Spain

Tel/Fax +34 9l 7293503

Email drubiorodriguez@healthvalue.org
Objective: According to a recent randomized, double-blind clinical trial comparing the combination of voriconazole and anidulafungin (VOR+ANI) with VOR monotherapy for invasive aspergillosis (IA) in patients with hematologic disease or with hematopoietic stem cell transplant, mortality was lower after 6 weeks with VOR+ANI than with VOR monotherapy in a post hoc analysis of patients with galactomannan-based IA. The objective of this study was to compare the cost-effectiveness of VOR+ANI with VOR, from the perspective of hospitals in the Spanish National Health System.

Methods: An economic model with deterministic and probabilistic analyses was used to determine costs per life-year gained (LYG) for VOR+ANI versus VOR in patients with galactomannan-based IA. Mortality, adverse event rates, and life expectancy were obtained from clinical trial data. The costs (in 2015 euros [€]) of the drugs and the adverse event-related costs were obtained from Spanish sources. A Tornado plot and a Monte Carlo simulation (1,000 iterations) were used to assess uncertainty of all model variables.

Results: According to the deterministic analysis, for each patient treated with VOR+ANI compared with VOR monotherapy, there would be a total of 0.348 LYG (2.529 vs 2.181 years, respectively) at an incremental cost of $€ 5,493$ ( $€ 17,902$ vs $€ 12,409$, respectively). Consequently, the additional cost per LYG with VOR+ANI compared with VOR would be $€ 15,785$. Deterministic sensitivity analyses confirmed the robustness of these findings. In the probabilistic analysis, the cost per LYG with VOR+ANI was $€ 15,774$ (95\% confidence interval: $€ 15,763-16,692)$. The probability of VOR+ANI being cost-effective compared with VOR was estimated at $82.5 \%$ and $91.9 \%$, based on local cost-effectiveness thresholds of $€ 30,000$ and $€ 45,000$, respectively.

Conclusion: According to the present economic study, combination therapy with VOR+ANI is cost-effective as primary therapy of IA in galactomannan-positive patients in Spain who have hematologic disease or hematopoietic stem cell transplant, compared with VOR monotherapy. Keywords: anidulafungin, cost-effectiveness, galactomannan, invasive aspergillosis, voriconazole

\section{Introduction}

Invasive aspergillosis (IA) is a life-threatening infection, particularly in patients with hematologic disease or who have received hematopoietic stem cell transplantation (HSCT). ${ }^{1}$ Although survival has increased in recent years due to advances in diagnosis and new antifungal drugs, ${ }^{2}$ prognosis of IA continues to be suboptimal, 
with an attributable mortality of $42 \%-64 \%$. $^{3,4}$ Combination therapies may improve antifungal efficacy but do so at increased cost.

The public price of treating diagnosis-related group number 580 (systemic infections and parasitic disorders except septicemia with major complications), which includes aspergillosis, has been reported to be $€ 7,173$ in Madrid ${ }^{5}$ and $€ 9,072$ in Navarra, Spain. ${ }^{6}$ In a German study published in 2014, which looked at Spanish hospital data on the cost of antifungal therapy of IA, voriconazole (VOR) had a lower total treatment cost compared with liposomal amphotericin $\mathrm{B}$ (€8,032 and $€ 10,516$, respectively). ${ }^{7}$ Given the significant health and economic impact of IA, it is extremely important to select the most appropriate IA therapy strategy.

Accurate diagnosis of IA is difficult, because the health status of the patient often precludes invasive procedures and biopsy sampling. Given that early diagnosis is fundamental for improving therapeutic outcomes, rapid detection of galactomannan antigen in serum or bronchoalveolar lavage is useful in the early diagnosis and monitoring of IA. ${ }^{8}$

According to a recent clinical trial in patients with hematologic disease or HSCT, mortality at 6 weeks of IA therapy was lower with a combination of voriconazole and anidulafungin (VOR+ANI) than with VOR monotherapy and was lower in the subgroup of patients receiving combination therapy who had probable IA based on positive galactomannan antigen testing than in the overall population of patients receiving combination therapy. ${ }^{9}$ The objective of our study was to compare the cost-effectiveness of both therapies, from the perspective of hospitals in the Spanish National Health System.

\section{Methods}

\section{Economic model}

Using an economic model, the efficacy of VOR+ANI combination therapy was compared with VOR monotherapy for the treatment of IA in a hypothetical cohort of 1,000 galactomannan-positive patients. The model consisted of a decision tree (Figure 1) predicting outcomes after 6 weeks of therapy. The analysis considered the following variables: mortality or survival rate of the patient; probability of adverse events (AEs) occurring or not; probability of any AEs occurring being serious or mild-to-moderate; costs of antifungal therapy, AE-related costs, and costs of hospital stays (ward and intensive care unit [ICU]); and life expectancy in patients with HSCT who respond satisfactorily to antifungal therapy for IA. Efficacy and toxicity data were obtained from a clinical trial reporting on VOR+ANI combination therapy in 108 patients and VOR monotherapy in 110 patients (NCT00531479). ${ }^{9}$

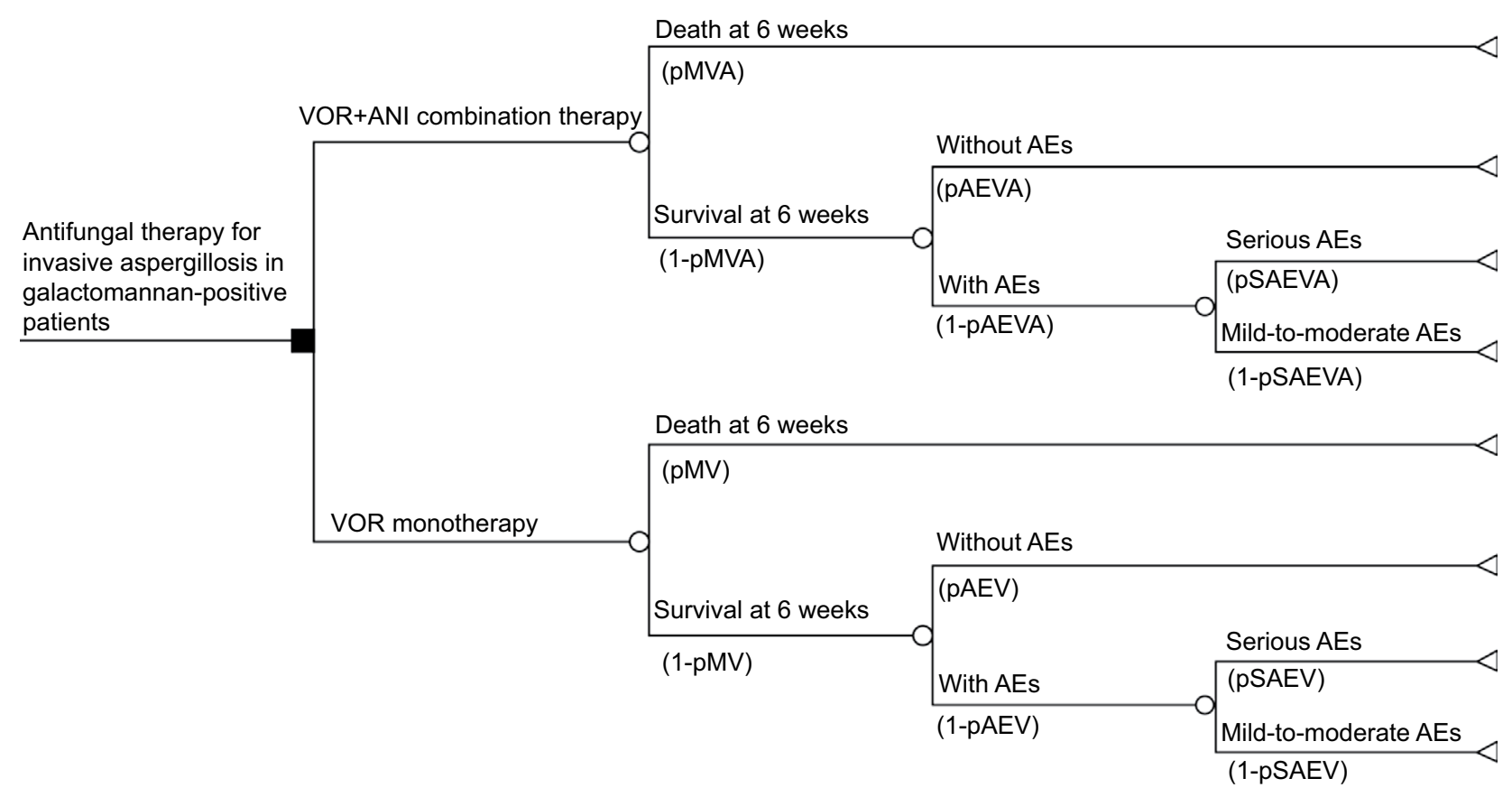

Figure I Decision tree model.

Note: I- Represents the complementary probability.

Abbreviations: AE, adverse event; ANI, anidulafungin; PAEV, probability of AEs occurring with VOR monotherapy; pAEVA, probability of AEs occurring with VOR+ANI combination therapy; $P M V$, probability of mortality with VOR monotherapy; pMVA, probability of mortality with VOR+ANI combination therapy; PSAEV, probability of serious AEs occurring with VOR monotherapy; PSAEVA, probability of serious AEs occurring with VOR+ANI combination therapy; VOR, voriconazole. 
The main model inputs are presented in Table 1. Deterministic and probabilistic analyses were conducted. The base-case deterministic analysis was constructed using mean values for each variable; sensitivity analyses modifying each parameter were also performed for all of the variables presented in Table 1. Specifically, the sensitivity of the result to variation in the following parameters was assessed (for VOR+ANI or VOR): probability of mortality, duration of hospital stay, life expectancy, drug acquisition cost; probability of occurrence of mild-to-moderate or serious AEs, and costs related to mild-to-moderate or serious AEs. Variation in the duration of antifungal therapy (base-case \pm 7 days) was also considered. Probabilistic analysis was conducted using second-order Monte Carlo simulations ${ }^{10}$ (1,000 iterations), with the objective of assessing the uncertainty of all variables, which is indicated in Table 1. Monte Carlo simulations use computerized statistical sampling techniques to obtain a probabilistic approximation of the solution of an equation or mathematical model. ${ }^{11}$ The rates were adjusted to beta distributions and the costs to gamma distributions. ${ }^{10}$
The economic model was applied using the TreeAge Pro 2014 program (TreeAge Software, Inc., Williamstown, MA, USA). All prices and costs in the model were expressed in 2015 euros $(€)$, with the exception of the $7.5 \%$ reduction of the price of ANI (Ecalta ${ }^{\circledR}$; Pfizer Inc., NY, USA) in Spain that was authorized in early 2016.

\section{Mortality}

As shown in Table 1, according to the clinical trial of Marr et al, ${ }^{9}$ mortality after 6 weeks of IA therapy was significantly lower with VOR+ANI than with VOR monotherapy in galactomannan-positive patients $(15.7 \%$ and $27.3 \%$, respectively; $p=0.037$ ).

\section{Adverse events}

A serious $\mathrm{AE}$ was defined as an event for which the patient outcome is death, life-threatening, hospitalization, or permanent disabilities or damage, in accordance with guidance issued by the US Food and Drug Administration..$^{12}$ The overall $\mathrm{AE}$ rate in the galactomannan-positive patient group was

Table I Economic model assumptions

\begin{tabular}{|c|c|c|c|c|c|c|c|}
\hline Item & Average & Interval $^{\mathbf{a}}$ & SD & Distribution & Alpha & Beta & References \\
\hline \multicolumn{8}{|c|}{ Mortality rates, $\%$} \\
\hline $\mathrm{VOR}+\mathrm{ANI}$ & 15.74 & 10.07-23.77 & 3.50 & Beta & 16.93 & 90.62 & Marr et al ${ }^{9}$ \\
\hline VOR & 27.27 & $19.82-36.26$ & 4.19 & & 30.51 & 81.35 & \\
\hline \multicolumn{8}{|c|}{ Treatment-related AEs, \% } \\
\hline $\mathrm{VOR}+\mathrm{ANI}$ & 69.74 & $63.49-75.33$ & 3.02 & Beta & 160.49 & 69.65 & Marr et $\mathrm{al}^{9}$ \\
\hline VOR & 62.39 & $55.92-68.45$ & 3.20 & & 142.62 & 85.98 & \\
\hline \multicolumn{8}{|c|}{ Serious treatment-related AEs, \% } \\
\hline $\mathrm{VOR}+\mathrm{ANI}$ & 19.50 & $14.09-26.34$ & 3.13 & Beta & 31.12 & 128.48 & Marr et al ${ }^{9}$ \\
\hline VOR & 14.18 & $9.37-20.90$ & 2.94 & & 19.85 & 120.06 & \\
\hline \multicolumn{8}{|c|}{ Antifungal treatment $\cos ^{\mathrm{b}} €$} \\
\hline $\mathrm{VOR}+\mathrm{ANI}$ & $10,899.89$ & $|0,8| 7.0|-| 1|| 26.86$, & 79.04 & Gamma & $|9,015.6|$ & 0.57 & Ministerio de Sanidad Servicios Sociales e \\
\hline VOR & $6,054.74$ & $5,97 \mid .86-6,281.71$ & 79.04 & & $5,867.56$ & 1.03 & $\begin{array}{l}\text { Igualdad; }{ }^{16} \text { Consejo General de Colegios } \\
\text { Oficiales de Farmacéuticos }{ }^{13}\end{array}$ \\
\hline \multicolumn{8}{|c|}{ Mild to moderate $A E$ unit $\operatorname{cost}^{c} €$} \\
\hline Both & 457.04 & $365.64-548.45$ & 46.64 & Gamma & 96.04 & 4.76 & $\begin{array}{l}\text { Ojeda et al; }{ }^{17} \text { Martin-Iglesias; }{ }^{18} \text { Llibre- } \\
\text { Codina et al; }{ }^{19} \text { Presidente de la Gerencia } \\
\text { Regional de Salud; }{ }^{20} \text { Servicio Madrileño de } \\
\text { Salud; }{ }^{5} \text { Marr et al }{ }^{9}\end{array}$ \\
\hline \multicolumn{8}{|c|}{ Serious $A E$ unit $\operatorname{cost}^{c} €$} \\
\hline Both & $\mathrm{I}, 859.57$ & $\mathrm{I}, 487.66-2,23 \mathrm{I} .49$ & 189.75 & Gamma & 96.04 & 19.36 & $\begin{array}{l}\text { Ojeda et al; }{ }^{17} \text { Ministerio de Sanidad } \\
\text { Servicios Sociales e Igualdad; }{ }^{21} \text { Holstenson } \\
\text { et al } ;{ }^{22} \text { Isla et al } ;{ }^{23} \text { Servicio Madrileño de } \\
\text { Salud; }{ }^{5} \text { Marr et al }{ }^{9}\end{array}$ \\
\hline \multicolumn{8}{|c|}{ Hospital stay $\cos t^{\mathrm{d}} €$} \\
\hline $\mathrm{VOR}+\mathrm{ANI}$ & $6,815.59$ & $5,|26.4|-8,728.69$ & 918.95 & Gamma & 55.01 & 123.90 & Peiró et al; ${ }^{38}$ Asensio et al:;4 Marr et al ${ }^{9}$ \\
\hline VOR & $6,274.84$ & $4,645.32-8,127.05$ & 888.20 & & 49.91 & 125.72 & \\
\hline \multicolumn{8}{|c|}{ Life expectancy ${ }^{\mathrm{e}}$ years } \\
\hline Both & 3.00 & $2.70-3.30$ & 0.15 & Gamma & 384.16 & 0.01 & $\begin{array}{l}\text { Jansen et al } ; 5 \text { Jansen et al } ;{ }^{26} \text { Ament et al } ;{ }^{27} \\
\text { Krueger and Nelson }{ }^{28}\end{array}$ \\
\hline
\end{tabular}

Notes: anterval is given as $95 \% \mathrm{Cl}$ unless otherwise indicated; body weight in Spanish adults (70.0 kg; $95 \%$ Cl: 67.76-76.13 kg) obtained from Spanish official figures ${ }^{16}$;

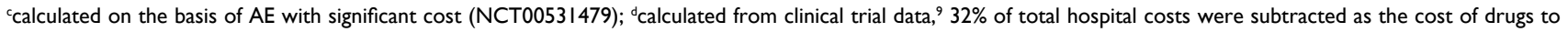
avoid double-counting; ${ }^{38}$ elife expectancy of recipients of a hematopoietic stem cell transplant who survive after invasive aspergillosis treatment is $\sim 3$ years. ${ }^{25-28}$ Interval: $\pm 10 \%$. Abbreviations: $\mathrm{AE}$, adverse event; $\mathrm{ANI}$, anidulafungin; $\mathrm{Cl}$, confidence interval; SD, standard deviation; VOR, voriconazole. 
higher with VOR+ANI (69.7\%) than with VOR monotherapy (62.4\%); the rate of serious AEs was also higher (19.5\% and $14.2 \%$, respectively; Table 1$){ }^{9}$

\section{Drug acquisition costs}

The acquisition costs of VOR (Vfend ${ }^{\circledR}$; Pfizer Inc.) and ANI $\left(\right.$ Ecalta $\left.^{\circledR}\right)$ were obtained from the official manufacturer's sales prices in Spain, including the recently authorized mandatory discount of $7.5 \%$ for ANI (Table 2 ). ${ }^{13}$ We also considered the dosage schedules recommended in the Summary of Product Characteristics of both drugs ${ }^{14,15}$ and, in the case of VOR, the average body weight of adults in Spain $(70.0 \mathrm{~kg} ; 95 \%$ confidence interval [CI]: 67.8-76.1 kg), obtained from Ministry of Health databases (Table 2). ${ }^{16}$ Patients were assumed to receive treatment with ANI (200 mg on day 1, followed by $100 \mathrm{mg}$ every subsequent day of treatment) for at least 2 weeks and no more than 4 weeks.

\section{AE-related costs}

The costs of serious and mild-to-moderate AEs were calculated from the rates described by Marr et $\mathrm{al}^{9}$ and from the unit costs of handling the AE, obtained from Spanish sources (Table 1). ${ }^{5,17-23}$

\section{Hospitalization costs}

The frequencies of hospitalization (within a timeframe of 6 weeks) with VOR (31.7\%) and VOR+ANI (30.4\%) on the ward and in the ICU were obtained from data reported by Marr et al $;{ }^{9}$ length of hospital stay for VOR+ANI and VOR alone in the general ward (36.0 and 34.4 days, respectively) and the ICU (14.2 and 13.7 days, respectively) were also taken from this clinical trial. Unit costs of a 1-day stay on the general ward (€457; 95\% CI: €366-548) and ICU (€1,860; 95\% CI: $€ 1,488-2,231)$ were obtained from a previously published Spanish study (Table 1). ${ }^{24}$

\section{Life expectancy (time horizon)}

The life expectancy of patients with HSCT who survive after antifungal therapy for IA is $\sim 3$ years. ${ }^{25-28}$ Therefore, the time horizon (the duration of monitoring of the hypothetical patients of the model) of the presented model was 3.0 years (95\% CI: $2.7-3.3$ years; Table 1 ).

\section{Presentation of results}

The results are presented as average cost per life-year gained (LYG) by galactomannan-positive patients with IA treated with VOR+ANI and VOR monotherapy and as differences in costs and life-years between the two therapy strategies. Cost per LYG for VOR+ANI compared with VOR monotherapy was calculated. For the probabilistic analysis, cost-effectiveness planes were calculated and probability of cost-effectiveness estimated relative to local willingness-to-pay thresholds of $€ 30,000$ and $€ 45,000$ as previously reported. ${ }^{29,30}$

\section{Results}

\section{Deterministic analysis}

In each hypothetical cohort of 1,000 patients receiving either VOR+ANI combination therapy or VOR alone, 157 and 273 deaths were expected to occur, respectively. In surviving patients, 256 and 274 AEs were predicted in patients

Table 2 Drug acquisition cost calculation

\begin{tabular}{|c|c|c|c|c|c|c|}
\hline Body weight $^{\text {a }}$ (kg) & Item & Day I & Days 2-7 & Days 2-14 & Days 8-42 & Total cost (€) \\
\hline \multicolumn{7}{|l|}{ Voriconazole } \\
\hline \multirow[t]{3}{*}{70.0} & Dose $(\mathrm{mg} / \mathrm{kg})^{\mathrm{b}}$ & 840 & 560 & - & 600 & - \\
\hline & Administration ${ }^{c}$ & IV & IV & - & Oral & - \\
\hline & Cost $(€)^{d}$ & 517.95 & $2,071.79$ & - & $3,465.00$ & $6,054.74$ \\
\hline \multirow[t]{3}{*}{67.8} & Dose $(\mathrm{mg} / \mathrm{kg})^{\mathrm{b}}$ & 813 & 542 & - & 600 & - \\
\hline & Administration ${ }^{c}$ & IV & IV & - & Oral & - \\
\hline & Cost $(€)^{d}$ & 501.37 & $2,005.48$ & - & $3,465.00$ & $5,971.86$ \\
\hline \multirow[t]{3}{*}{76.1} & Dose $(\mathrm{mg} / \mathrm{kg})^{\mathrm{b}}$ & 914 & 609 & - & 600 & - \\
\hline & Administration ${ }^{c}$ & IV & IV & - & Oral & - \\
\hline & Cost $(€)^{d}$ & 563.34 & - & $2,253.36$ & $3,465.00$ & $6,281.71$ \\
\hline \multicolumn{7}{|l|}{ Anidulafungin } \\
\hline \multirow[t]{3}{*}{ Any } & Dose $(m g)^{b}$ & 200 & - & 100 & - & \\
\hline & Administration ${ }^{c}$ & IV & IV & IV & - & - \\
\hline & Cost $(€)$ & 646.02 & - & $4,199.13$ & - & $4,845.15$ \\
\hline
\end{tabular}

Notes: ${ }^{a}$ Body weight in Spanish adults $(70.0 \mathrm{~kg} ; 95 \% \mathrm{Cl}: 67.76-76.13 \mathrm{~kg})$ obtained from Spanish official figures ${ }^{16,39}$; bdoses calculated from Marr et al'; ' 0 btained from Summary of Product Characteristics ${ }^{13}$; drug acquisition costs were obtained from the approved ex-factory prices in Spain with official $7.5 \%$ discount rate as of early $2016 .{ }^{13}$ Abbreviations: $\mathrm{Cl}$, confidence interval; IV, intravenous. 
receiving either VOR+ANI combination therapy or VOR alone, respectively. More serious AEs were expected with VOR+ANI $(n=50)$ than with VOR monotherapy $(n=39)$.

The median duration of VOR+ANI combination therapy was 14 days (range: 1-29 days); the median duration of VOR monotherapy was 42 days (range: $1-48$ days). ${ }^{9}$ As shown in Table 3 , the average life expectancy per patient was 2.5 years with VOR+ANI and 2.2 years with VOR monotherapy (an increase of $0.348 \mathrm{LYG}$ with VOR+ANI). The average cost per patient of antifungal therapy for IA was $€ 17,902$ with VOR+ANI and $€ 12,409$ with VOR monotherapy (an additional cost of $€ 5,493$ with VOR+ANI). Consequently, the incremental cost per LYG was $€ 15,785$ with VOR+ANI versus VOR.

The results of the univariate sensitivity analyses are represented in the Tornado plot (Figure 2). The variables that most influenced the results were mortality probabilities for each of the compared therapy strategies. The variation in the mortality probability with VOR+ANI $(0.10-0.24)$ would lead to a cost per LYG with VOR+ANI versus VOR monotherapy from $€ 10,669$ to $€ 52,144$. The variation in the mortality probability with VOR monotherapy $(0.20-0.36)$ would lead to a cost per LYG with combination from $€ 8,924$ to $€ 44,509$ (Figure 2). When the duration of antifungal therapy was varied by \pm 7 days relative to the base-case analysis, the cost per LYG was $€ 9,287$ with VOR+ANI versus $€ 22,282$ with VOR monotherapy.

\section{Probabilistic analysis}

In the probabilistic analysis, the cost per LYG with VOR+ANI was $€ 15,774$ (95\% CI: $€ 15,763-16,692$; Table 4). The probability that VOR+ANI would be considered cost-effective compared with VOR was estimated at $82.5 \%$ and $91.9 \%$ at locally established willingness-to-pay thresholds of $€ 30,000$ and $€ 45,000$, respectively (Figure 3 ). The cost-effectiveness acceptability curves for both therapy options are presented in Figure 4.

\section{Discussion}

The pharmacoeconomic model used in this study suggests an increase of 0.348 LYG with VOR+ANI compared with VOR monotherapy for galactomannan test-based IA in each patient with hematologic disease or HSCT. According to the study by
Rodriguez-Tudela et al, there were 419 such patients across Spain in $2010 .{ }^{31}$ Therefore, widespread VOR+ANI combination therapy in patients with hematologic disease or HSCT in Spain could provide an annual gain of $\sim 146$ years compared with VOR monotherapy. Similarly, our findings suggest that the probability that VOR+ANI combination therapy of IA is cost-effective compared with VOR monotherapy is $82.5 \%$ at a previously established local willingness-to-pay threshold of $€ 30,000$ per LYG (91.9\% at a threshold of $€ 45,000$ per LYG). ${ }^{29,30}$

Certain limitations and inconsistencies of this study must be taken into account when considering these results. This was a theoretical model, which, by definition, was a simulation of real-world clinical practice. Additionally, efficacy and AE data were obtained from an explanatory double-blind, randomized clinical trial (NCT00531479), ${ }^{9}$ as no data from pragmatic clinical trials were available. ${ }^{32}$ Consequently, the results of the economic analysis are applicable only to patients with similar characteristics to those included in that clinical trial. Also, the lower mortality of the subgroup of patients who received VOR+ANI combination therapy for IA indicated by galactomannan testing in the trial reported by Marr et $\mathrm{al}^{9}$ was determined by means of a post hoc analysis, with associated methodological limitations. ${ }^{33}$ As noted by Marr et al, ${ }^{9}$ further work is required to confirm the results obtained in the combination therapy subgroup; our economic model was, therefore, also dependent on such limitations. The highest mortality probabilities used in the deterministic sensitivity analyses with VOR+ANI and VOR monotherapy lead to costs per LYG with the combination above $€ 30,000$ per LYG.

Reliability of the presented findings were assessed by Monte Carlo simulation. ${ }^{34}$ In clinicoeconomic research, this statistical approach is used to predict individual clinical outcomes for a hypothetical cohort of patients using theoretical sampling of random variables, the behavior of which is described by means of given sampling distributions. ${ }^{35}$ Therefore, the Monte Carlo simulation shows the effect of the random changes conducted on different parameters and consequently imitates the actual clinical development of the patients. The reliability of the result obtained was effectively confirmed by the sensitivity analyses conducted. According to our probabilistic sensitivity analysis, the probability of VOR+ANI being cost-effective compared with VOR

Table 3 Deterministic analysis results: base-case

\begin{tabular}{llllll}
\hline Treatment & Costs $(\boldsymbol{\epsilon})$ & Cost differences $(\boldsymbol{\epsilon})$ & Life-years & LYG & Cost per LYG $^{\mathbf{a}}(\boldsymbol{\epsilon})$ \\
\hline VOR+ANI & 17,902 & 5,493 & 2.529 & 0.348 & 15,785 \\
VOR & 12,409 & & 2.181 & \\
\hline
\end{tabular}

Notes: Incremental cost-effectiveness ratio (cost per LYG with VOR+ANI versus VOR monotherapy).

Abbreviations: ANI, anidulafungin; LYG, life-year gained; VOR, voriconazole. 


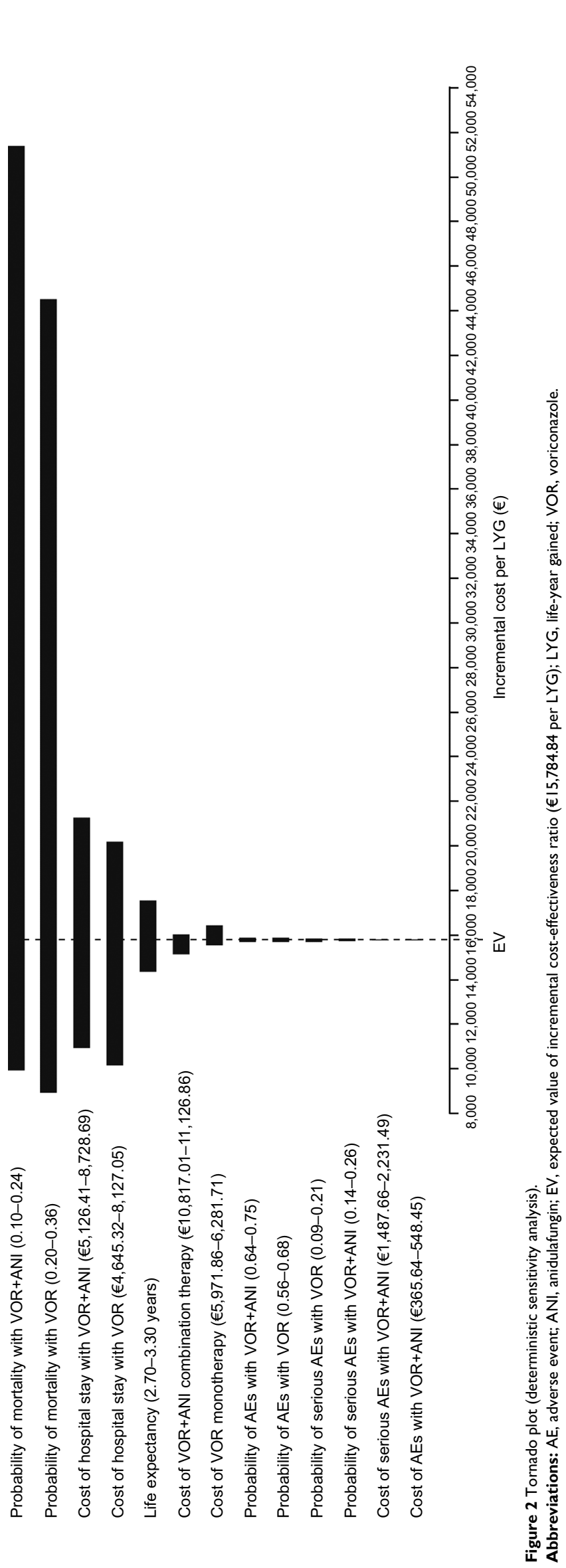

Table 4 Probabilistic analysis results

\begin{tabular}{llll}
\hline & Cost, $\boldsymbol{\epsilon}(\mathbf{9 5 \%} \mathbf{C l})$ & LYG (95\% Cl) & $\begin{array}{l}\text { Cost per LYGa } \\
(\mathbf{9 5 \%} \mathbf{~ C l})\end{array}$ \\
\hline VOR+ANI & 18,063 & 2.534 & 15,774 \\
& $(16,431-20,020)$ & $(2.224-2.843)$ & $(15,763-16,692)$ \\
VOR & 12,385 & 2.174 & \\
& $(10,720-14,206)$ & $(1.862-2.495)$ & \\
\hline
\end{tabular}

Notes: alncremental cost-effectiveness ratio (cost per LYG with VOR+ANI combination therapy vs VOR monotherapy).

Abbreviations: ANI, anidulafungin; Cl, confidence interval; LYG, life-year gained; VOR, voriconazole.

monotherapy was $82.5 \%$ versus $91.9 \%$, at local willingnessto-pay thresholds of $€ 30,000$ and $€ 45,000$ per LYG, respectively. ${ }^{29,30}$ All costs used in the model were taken from Spanish sources, to ensure that the results accurately reflected routine clinical practice in the Spanish healthcare system.

It was not possible to compare the results and procedures of this study with those from another country, as no similar economic analyses comparing VOR+ANI combination therapy with VOR monotherapy for IA in galactomannan-positive patients were identified. Nor were any studies found that compared the efficacy of other antifungal therapy strategies in IA or in other indications in galactomannan-positive patients. In published studies, only the unit cost of the galactomannan test was assessed, and not its diagnostic role as a possible determinant of the cost-effectiveness of IA therapy. ${ }^{36,37}$ No costs were considered for additional diagnostic tests given as part of a full diagnostic workup or as follow-up to galactomannan antigen testing, under the assumption that these costs would not be substantial.

\section{Conclusion}

On the basis of the findings of our economic model and probabilistic sensitivity analysis, combination therapy with VOR+ANI may be cost-effective as the primary therapy for IA in galactomannan-positive patients in Spain, compared with VOR monotherapy.

\section{Acknowledgments}

Editorial support was provided by Martin Bell, $\mathrm{PhD}$, at Complete Medical Communications, and was funded by Pfizer.

These results differ slightly from those presented in the poster at the ISPOR Congress, Milan, November 2015, due to a $7.5 \%$ reduction of the price of anidulafungin in Spain, which was authorized in early 2016.

\section{Authors contribution}

CRT and DRR developed the economic model. CP, JAB, and FJM reviewed the economic model. All authors had full access to the data, and contributed heavily to the analysis and 
A

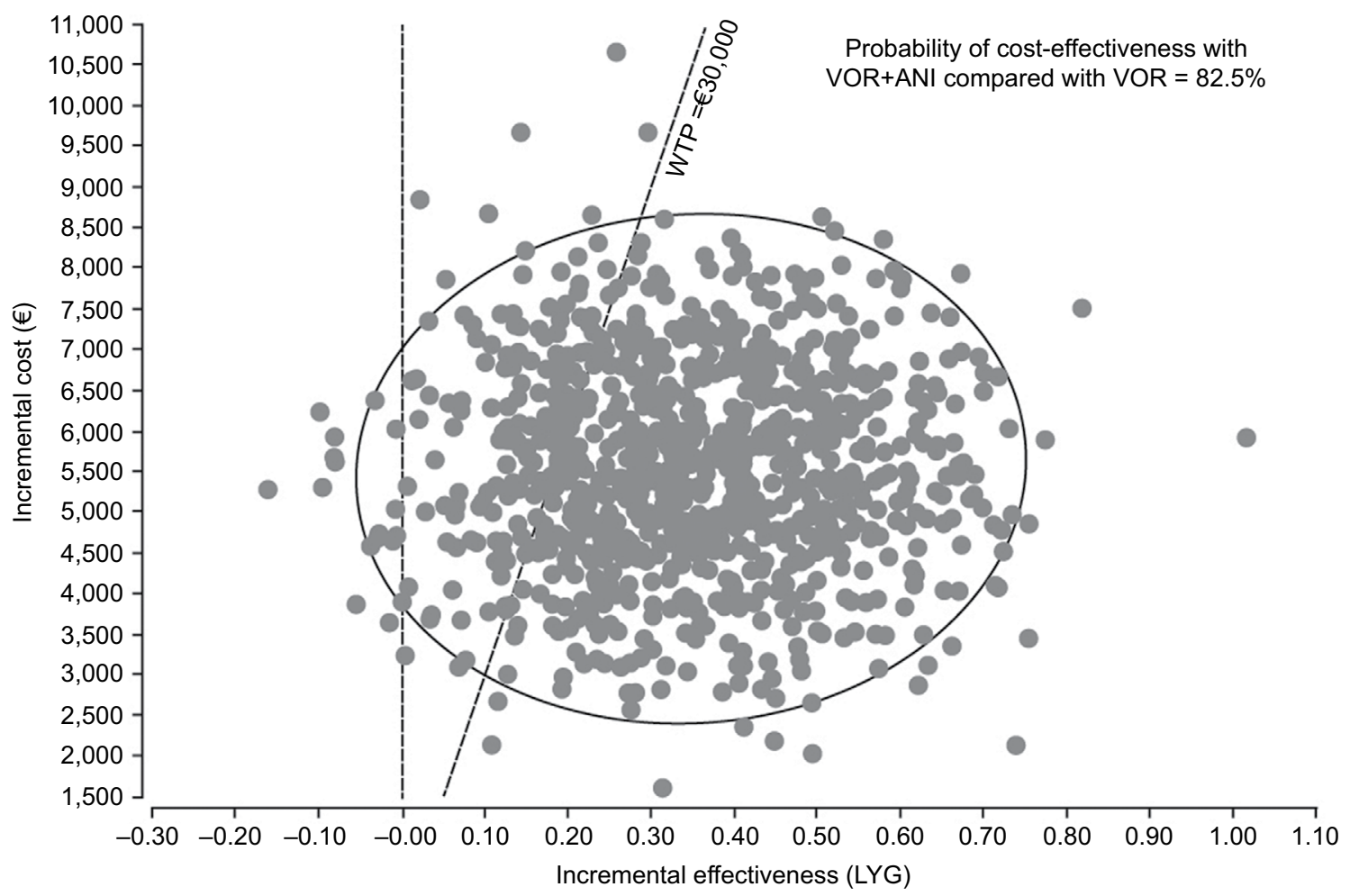

B

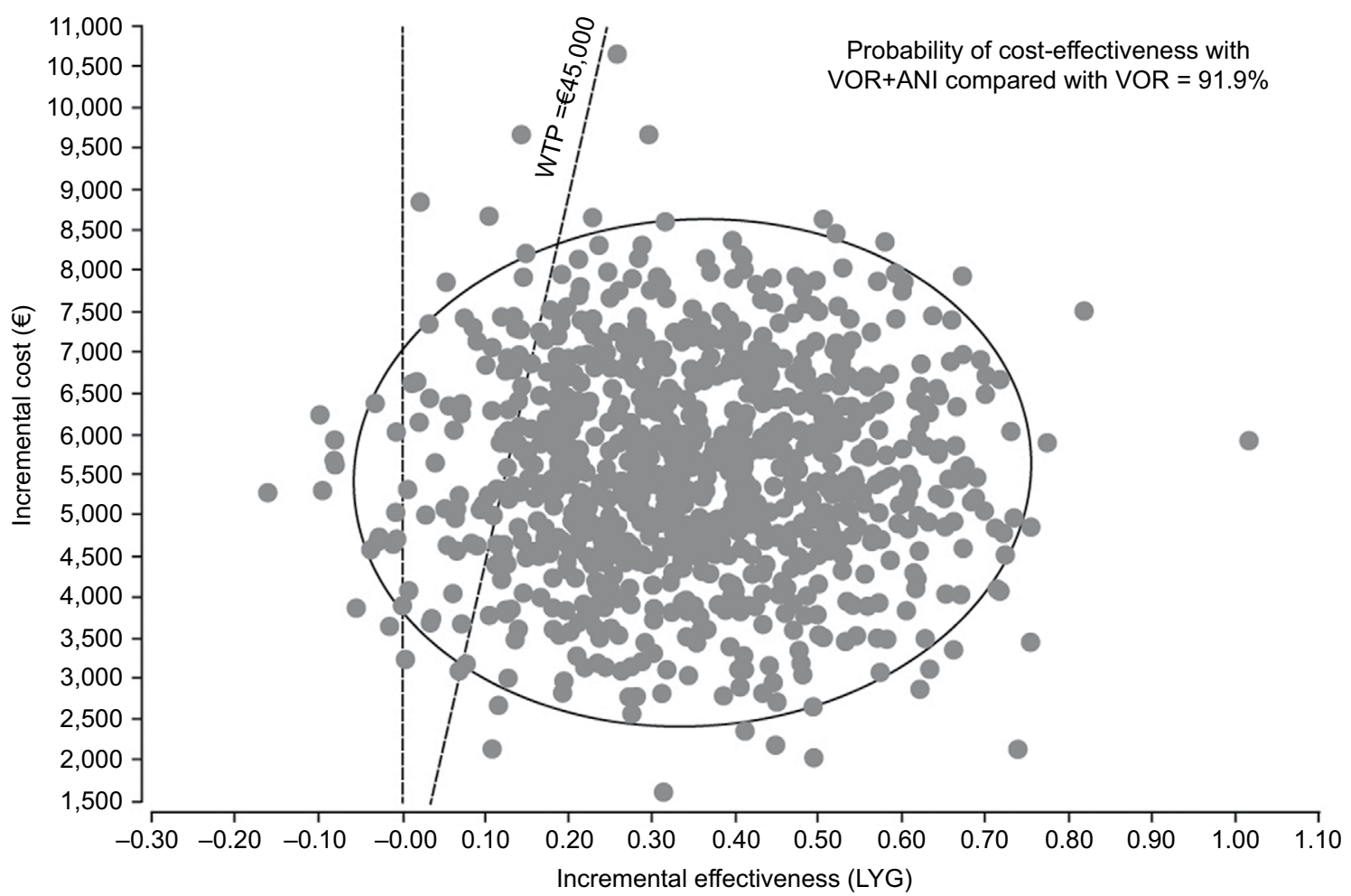

Figure 3 Cost-effectiveness plane (Monte Carlo simulation) at: (A) a willingness-to-pay threshold of $€ 30,000$; and (B) a willingness-to-pay threshold of $€ 45,000$. Abbreviations: ANI, anidulafungin; LYG, life-year gained; VOR, voriconazole; WTP, willingness-to-pay threshold.

interpretation of the results. All authors contributed to the drafting of the manuscript and to the subsequent revisions at each stage of the manuscript development. All authors have approved the final version for publication and agreed to remain accountable for the accuracy and integrity of this work. CRT is the guarantor for the overall content of the paper. 


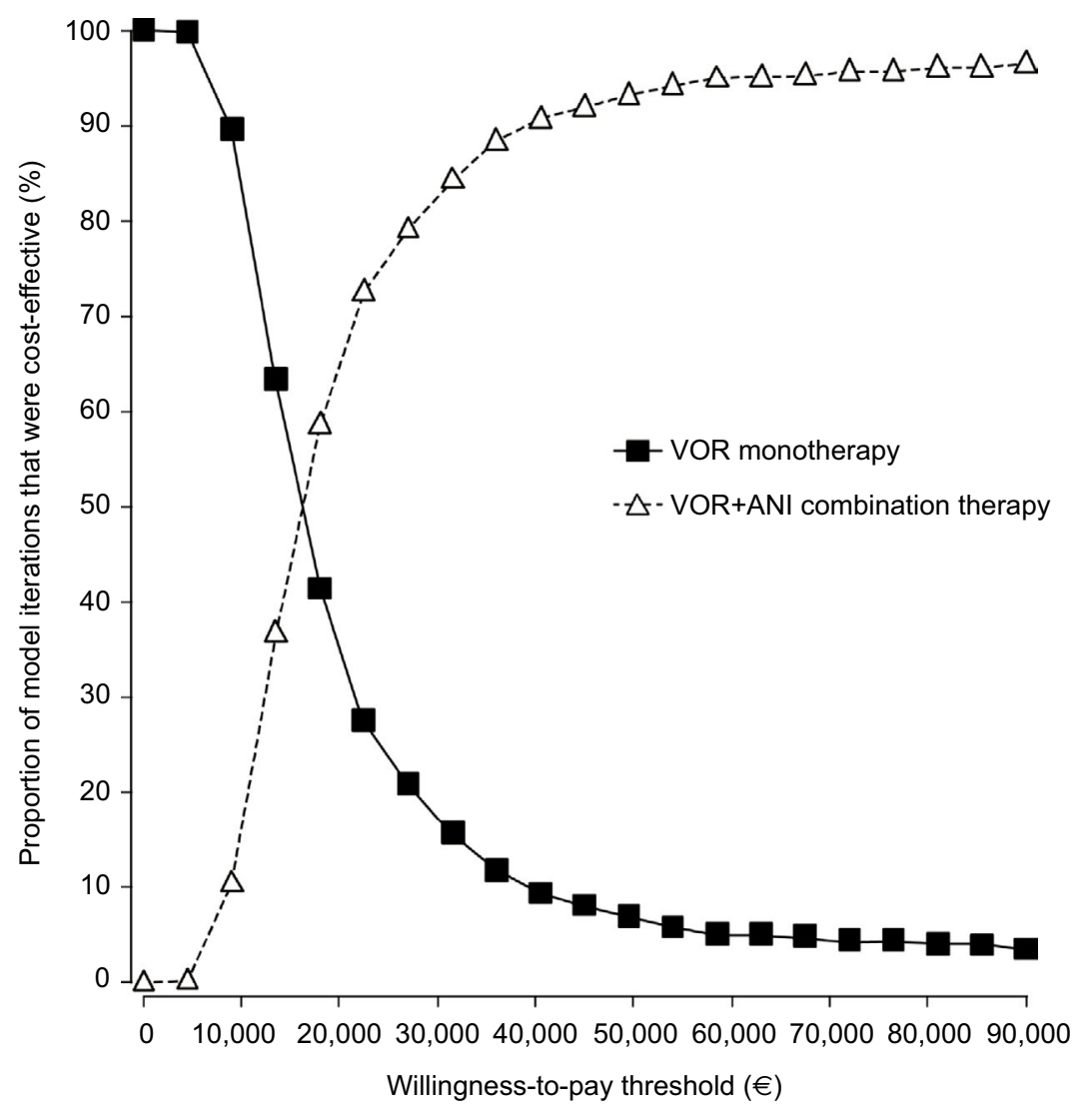

Figure 4 Cost-effectiveness acceptability curve.

Abbreviations: ANI, anidulafungin; VOR, voriconazole.

\section{Disclosure}

JAB, CP, and FJM are employees of Pfizer S.L.U. (Spain). WJH has received research grants from MSD Sharp \& Dohme/Merck and Pfizer; served on speaker bureaus for Alexion, Astellas, Basilea, Bristol-Myers Squibb, Chugai Pharma, Gilead, Janssen, MSD Sharp \& Dohme, and Pfizer; participated in advisory boards for Astellas, Gilead, MSD, and Pfizer; and received travel grants from Alexion, Astellas, MSD Sharp \& Dohme, Novartis, and Pfizer. CC is an employee of Pfizer Inc. (France). DRR and CRT have received honoraria from Pfizer Inc. in connection with the development of this manuscript. SG, JRA, IR, CV, J Maertens, J Mensa, and MB declare no conflicts of interest in this work.

\section{References}

1. Martín-Peña A, Aguilar-Guisado M, Espigado I, Cisneros JM. Antifungal combination therapy for invasive aspergillosis. Clin Infect Dis. 2014;59(10):1437-1445.

2. Upton A, Kirby KA, Carpenter P, Boeckh M, Marr KA. Invasive aspergillosis following hematopoietic cell transplantation: outcomes and prognostic factors associated with mortality. Clin Infect Dis. 2007;44(4):531-540.

3. Mihu CN, Kassis C, Ramos ER, Jiang Y, Hachem RY, Raad II. Does combination of lipid formulation of amphotericin B and echinocandins improve outcome of invasive aspergillosis in hematological malignancy patients? Cancer. 2010;116(22):5290-5296.
4. Pagano L, Caira M, Candoni A, et al. The epidemiology of fungal infections in patients with hematologic malignancies: the SEIFEM-2004 study. Haematologica. 2006;91(8):1068-1075.

5. Servicio Madrileño de Salud. Order 731/2013. [Updated 2013 April 13]. Available from: http://www.madrid.org/wleg/servlet/Servidor?o pcion $=$ VerHtml\&nmnorma $=8275 \&$ cdestado=P\#_ftn 1 . Accessed July 6, 2016.

6. Servicio Navarro de Salud-Osasunbidea. Resolution 626/2014. [Updated 2014 June 5]. Available from: http://www.boletinesoficiales.com/ documentacion/legislacion/documento/RESOLUCION-626-2014-5-junio-Director-Gerente-Servicio-Navarro-Salud-Osasunbidea-actualizantarifas-servicios-prestados,50,20140709,10/. Accessed July 6, 2016.

7. Ostermann H, Solano C, Jarque I, et al. Cost analysis of voriconazole versus liposomal amphotericin B for primary therapy of invasive aspergillosis among patients with haematological disorders in Germany and Spain. BMC Pharmacol Toxicol. 2014;15:52.

8. Jarque I, Andreu R, Salavert M, et al. [Value of Aspergillus galactomannan antigen detection in the diagnosis and follow-up of invasive aspergillosis in hematological patients]. Rev Iberoam Micol. 2003;20(3):116-118. Spanish.

9. Marr KA, Schlamm HT, Herbrecht R, et al. Combination antifungal therapy for invasive aspergillosis: a randomized trial. Ann Intern Med. 2015;162(2):81-89.

10. Brigg A, Sculpher M, Claxton K. Decision Modelling for Health Economic Evaluation. Oxford, UK: Oxford University Press; 2006.

11. US Environmental Protection Agency. EPA/630/R-97/001 Guiding principles for Monte Carlo analysis. [Updated 1997 March 1]. Available from: https://www.epa.gov/sites/production/files/2014-11/documents/ montecar.pdf. Accessed July 6, 2016.

12. US Food and Drug Administration. What is a serious adverse event? [Updated 2016 January 2]. Available from: http://www.fda.gov/Safety/ MedWatch/HowToReport/ucm053087.htm. Accessed January 8, 2016. 
13. Consejo General de Colegios Oficiales de Farmacéuticos. Bot Plus 2.0. [Updated 2016 January 26]. Available from: https://botplusweb. portalfarma.com/. Accessed June 25, 2016.

14. European Medicines Agency. ECALTA summary of product characteristics. [Updated 2014 September 10]. Available from: https://www. medicines.org.uk/emc/medicine/22690. Accessed July 6, 2016.

15. European Medicines Agency. VFEND summary of product characteristics. [Updated 2015 December 24]. Available from: https://www. medicines.org.uk/emc/medicine/10059. Accessed July 6, 2016.

16. Ministerio de Sanidad Servicios Sociales e Igualdad. Talla y peso medio, según grupo de edad y sexo. [Updated 2001 July 13]. Available from: http://www.msssi.gob.es/estadEstudios/estadisticas/inforRecopilaciones/atlas/atlasDatos.htm. Accessed July 6, 2016.

17. Ojeda B, de Sande LM, Casado A, Merino P, Casado MA. Cost-minimisation analysis of pegylated liposomal doxorubicin hydrochloride versus topotecan in the treatment of patients with recurrent epithelial ovarian cancer in Spain. Br J Cancer. 2003;89(6):1002-1007.

18. Martin-Iglesias S. Estudio de costes y efectividad de la intervención enfermera en el estreñimiento crónico. [Updated 2006 November 24]. Available from: http://www.isciii.es/ISCIII/es/contenidos/fd-el-instituto/fd-organizacion/fd-estructura-directiva/fd-subdireccion-generalservicios-aplicados-formacion-investigacion/fd-centros-unidades/ fd-investen-isciii-2/docus/2006_X_encuentro_Investen_Albacete.pdf. Accessed July 7, 2016.

19. Llibre-Codina JM, Casado-Gómez MA, Sánchez-de la Rosa R, et al. [Cost of nucleoside analogue reverse transcriptase inhibitor-related toxicity in HIV-1-infected patients]. Enferm Infecc Microbiol Clin. 2007;25(2):98-107. Spanish.

20. Presidente de la Gerencia Regional de Salud. Resolution of July 1, 2008. [Updated 2008 July 1]. Available from: http://www.saludcastillayleon.es/institucion/es/recopilacion-normativa/asistencia-sanitaria/ prestaciones-derechos/resolucion-1-julio-2008-presidente-gerenciaregional-salud-. Accessed July 6, 2016.

21. Ministerio de Sanidad Servicios Sociales e Igualdad. Norma estatal de los AP GRD V23 por cluster 2009. [Updated 2009 November 6]. Available from: http://www.msps.es/estadEstudios/estadisticas/docs/ NormaGRD2009/NORMA_2009_AP_GRD_V23_CLUSTER.xls. Accessed July 6, 2016.

22. Holstenson E, Ringborg A, Lindgren P, et al. Predictors of costs related to cardiovascular disease among patients with atrial fibrillation in five European countries. Europace. 2011;13(1):23-30.

23. Isla D, González-Rojas N, Nieves D, Brosa M, Finnern HW. Treatment patterns, use of resources, and costs of advanced non-small-cell lung cancer patients in Spain: results from a Delphi panel. Clin Transl Oncol. 2011;13(7):460-471.

24. Asensio A, Bouza E, Grau S, Rubio-Rodríguez D, Rubio-Terrés C. [Cost of Clostridium difficile associated diarrhea in Spain]. Rev Esp Salud Publica. 2013;87(1):25-33. Spanish.
25. Jansen JP, Meis JF, Blijlevens NM, van’t Wout JW. Economic evaluation of voriconazole in the treatment of invasive aspergillosis in the Netherlands. Curr Med Res Opin. 2005;21(10):1535-1546.

26. Jansen JP, Kern WV, Cornely OA, et al. Economic evaluation of voriconazole versus conventional amphotericin B in the treatment of invasive aspergillosis in Germany. Value Health. 2006;9(1):12-23.

27. Ament AJ, Hübben MW, Verweij PE, et al. Economic evaluation of targeted treatments of invasive aspergillosis in adult haematopoietic stem cell transplant recipients in the Netherlands: a modelling approach. J Antimicrob Chemother. 2007;60(2):385-393.

28. Krueger KP, Nelson AC. Economic considerations in the treatment of invasive aspergillosis: a review of voriconazole pharmacoeconomic studies. Clinicoecon Outcomes Res. 2009;2009(1):35-43.

29. De Cock E, Miravitlles M, González-Juanatey JR, Azanza-Perea JR. Threshold value of the cost per year of life gained to recommend the adoption of health technologies in Spain: evidence from a literature review [Valor umbral del coste por año de vida ganado para recomendar la adopción de tecnologías sanitarias en España: evidencias procedentes de una revisión de la literatura]. Pharmacoecon Span Res Artic. 2007;4(3):97-107.

30. Sacristán JA, Oliva J, Del Llano J, Prieto L, Pinto JL. [What is an efficient health technology in Spain?]. Gac Sanit. 2002;16(4):334-343. Spanish.

31. Rodriguez-Tudela JL, Alastruey-Izquierdo A, Gago S, et al. Burden of serious fungal infections in Spain. Clin Microbiol Infect. 2015;21(2):183-189.

32. Schwartz D, Flamant R, Lellouch J. Clinical Trials. London, UK: Academic Press; 1980.

33. Curran-Everett D, Milgrom H. Post-hoc data analysis: benefits and limitations. Curr Opin Allergy Clin Immunol. 2013;13(3):223-224.

34. Rubio-Terrés C, Cobo E, Sacristán JA, Prieto L, Del Llano J, Badia X. [Analysis of uncertainty in the economic assessment of health interventions]. Med Clin (Barc). 2004;122(17):668-674. Spanish.

35. Paxton P, Curran PJ, Bollen KA, Kirby J, Chen F. Monte Carlo experiments: design and implementation. Structural Equation Modeling. 2001;8(2):287-312.

36. Martín-Peña A, Gil-Navarro MV, Aguilar-Guisado M, et al. Cost-effectiveness analysis comparing two approaches for empirical antifungal therapy in hematological patients with persistent febrile neutropenia. Antimicrob Agents Chemother. 2013;57(10):4664-4672.

37. Fung M, Kim J, Marty FM, Schwarzinger M, Koo S. Meta-analysis and cost comparison of empirical versus pre-emptive antifungal strategies in hematologic malignancy patients with high-risk febrile neutropenia. PLoS One. 2015;10(11):e0140930.

38. Peiró S, Gómez G, Rejas J, Guadarrama I, Blanca AB. Length of stay and antifungal treatments costs in patients with systemic mycosis: description and associated factors. Value Health. 2002;5(6):564.

39. Grau Cerrato S, Mateu-de Antonio J, Soto Alvarez J, et al. [Economic evaluation of voriconazole versus amphotericin B in the treatment of invasive aspergilosis]. Farm Hosp. 2005;29(1):5-10. Spanish.

\section{ClinicoEconomics and Outcomes Research}

\section{Publish your work in this journal}

ClinicoEconomics and Outcomes Research is an international, peerreviewed open-access journal focusing on health technology assessment, pharmacoeconomics and outcomes research in the areas of diagnosis, medical devices, and clinical, surgical and pharmacological intervention. The economic impact of health policy and health systems

\section{Dovepress}

organization also constitute important areas of coverage. The manuscript management system is completely online and includes a very quick and fair peer-review system, which is all easy to use. Visit http://www.dovepress.com/testimonials.php to read real quotes from published authors. 